\title{
Incidence of Placenta Previa, Management Andmaternal Outcome in Region of Taif. KSA.
}

\author{
Farzana Rizwan Arain ${ }^{1}$,Nisreen Aref Al Bizrah ${ }^{2}$, Abdul Aziz ${ }^{3}$,Afnan Jawad ${ }^{4}$, \\ Dareen Tarem ${ }^{5}$.
}

\author{
${ }^{1} \&^{2}$. obstetrics \&gynecology department Taif medical college, taif, KSA. \\ ${ }^{3}$ Senior resident ob \& gyne department King Abdul-Aziz specialist hospital \\ (KASH), KSA. \\ ${ }^{4}$ House officer King Abdul-Aziz specialist hospital (KASH)Taif, KSA \\ 5.House officer National Guard's hospital Jeddah.KSA
}

\begin{abstract}
Introduction: Ante partum hemorrhage is defined as any vaginal bleeding from the $24^{\text {th }}$ week of gestation till delivery. The number of cases of placenta previa and placenta accrete are increasing with the increasing caesarean section rate.Ante-partum hemorrhage is an important cause of maternal and fetal morbidity and mortality, despite modern improvement in obstetric practice and transfusion service. Placenta previa has been well documented to be associated with adverse maternal outcomes as well as neonatal outcomes. The indication for emergency peripartum hysterectomy in recent years has been changed from traditional uterine atony to abnormal placental implantation. The incidenceplacenta previais on rise because of the increasing rate of caesarean section being performed, and a trend of child bearing at a later age among the women' with the sametime the dangerous complication placentaaccreta which is associated with placenta previa and prior caesarean deliveries has also been increased in frequency ${ }^{16}$.

Material and Methods: This retrospective study was designed to see the incidence of placenta previa, ultrasound finding, management and maternal outcome in women suffering from placenta previa in region of Taifkingdom of Saudi Arabia.

Result: In two year total no of deliveries was 17757 out of that 213 was cases of placenta previa that makes the $1.19 \%$ of placenta previa out of total deliveries .Out of 5498 L.S.C.S, 213 cases were because of placenta previa which make about $3.8 \%$.out of 213 lscs 62 cases were done in emergency (29.1\%).and 151 was done as elective cases (70.8). as far as age women's were concerned highest percentage of placenta previa was seen in age group of $31-36$ years (35.2\%) followed by age group of 26-30years $(26.2 \%$..Out of 213 women of placenta previa $144(67.74 \%)$ women suffered from antepartum hemorrhage from moderate to severe bleeding .All women had lower segment caesarean section as mode of delivery whether in emergency or as an elective procedure dependent upon amount of bleeding, gestational age and condition of mother. All patent had ultrasound done to confirm the localization of placenta and to exclude placenta accreeta or percreeta. 14 patient underwent bilateral uterine ligation and because of bleeding and severe nature of placental adherence out of 213 women $56(26.29 \%)$ had caesarean hysterectomy and 6 patient received injuries to urinary tract in form of bladder injury or uretric injury which could be because of adhesion, excessive bleeding or difficult c/hysrectomy. By the bless of God there was no maternal death recorded in this period of study

Conclusion: In summary, history of previous lower segment caesarean section were found to be associated increased rate of placenta previa and its severe form i.e. placenta accreta.It is also concluded that with good antenatal care we can pick patient who are at high risk of placenta previa and its related risk.
\end{abstract}

Keywords: Placenta previa pr.lscs, peri partum hysterectomy

\section{Introduction}

Ante partum hemorrhage is defined as any vaginal bleeding from the $24^{\text {th }}$ week of gestation till delivery. The number of cases of placenta previa and placenta accrete are increasing with the increasing caesarean section rate ${ }^{1}$.One of The importantcauses of ante-partum hemorrhage is placenta previa in addition to abruption, which accounting for more than half the cases ${ }^{2}$. As far as Placentaprevia is concerned it can have serious adverse consequenceson both mother and baby, whichcould be an increased risk ofmaternal and neonatal mortality ${ }^{3,4,5}$.women suffering from placenta previa are also prone to have fetal growthrestriction, preterm delivery antenatal and intrapartumhemorrhage and even at great risk of post partum hemorrhage and women may require a massive blood transfusion with its all related complications .because of all these women some time need an emergency hysterectomy to save their life ${ }^{6,7,8}$. Ante-partum haemorrhage is an important cause of maternal andfetal morbidity and mortality, despite modern improvement in obstetric practice and transfusion

DOI: $10.9790 / 0853-151004122126 \quad$ www.iosrjournals.org $\quad 122 \mid$ Page


service. Placenta praevia has been well documented to be associated with adverse maternal outcomes as well as neonatal outcomes 9 . The indication for emergency peripartum hysterectomy in recent years has been changed from traditional uterine atony to abnormal placentaion which has now become a more common indication due to greater number of pregnant women with previous caesarean scar. Placenta praevia remains a risk factor for various maternal complications. There are higher incidence of postpartum hemorrhage (PPH) and blood transfusion in women with placenta praevia compared to general population ${ }^{10,11,12}$. Women with placenta praevia are more likely to deliver babies before 37 weeks with Apgar score of less than $7^{8}$. Studies also showed that there were higher admission to neonatal intensive care unit, stillbirth and death ${ }^{13}$. The true incidence of placenta previa is difficult to determine with any degree of certainty. The reported prevalence varies between as high of one in 100 to as low as one in 1000 live births ${ }^{14}$.In general this condition is found in 0.4 percent to 0.6 percent of all births. Placenta previa is a rare catastrophe associated with high maternal morbidity and mortality ${ }^{8}$. Placenta previa triples the rate of neonatal mortality, which is mediated mainly through preterm birth $^{15}$.in the era of increased caesarean section rate during antenatal periods there should be detection of placenta previa carefully in order to reduce the associated maternal and perinatal complications ${ }^{2}$. The incidenceplacenta previais on rise because of the increasing rate of caesarean section being performed, and a trend of child bearing at a later age among the women with the sametime The dangerous complication placenta accreta which is associated with placenta previa and prior caesarean deliveries has also increased in frequency ${ }^{16}$.

This retrospective study was designed to see the incidence of placenta previa, ultrasound finding, management and maternal outcome in women suffering from placenta previa in region of Taifkingdom of Saudi Arabia .

\section{Material and Methods}

This retrospective study was undertaken to evaluate the incidence of placenta previa, ultrasound finding, management and maternaloutcome in women suffering from placenta previa inKing Abdul-Aziz specialist hospital in regionof Taif,kingdom of Saudi Arabia. The inclusion criteria were all women who underwent caesarean section for placenta praevia in the Department of Obstetrics and Gynecology, KASH from January 2013 till December 2014. The hospital registration numbers of women who underwent caesarean section for placenta praevia were obtained from the operating theatre book. Using the hospital registration number, the medical notes of these women were retrieved from the record office. patients with pregnancy of more than 28 weeks duration, who were diagnosed to have placenta previa on ultrasound, their data was collected frommedical recordswhich included details from history, examination finding, investigation and relevant details of selected cases by using Performa, which included age, parity, gestational age, predisposing factors, h/o of previous $\mathrm{c}$-section .h/o dilatation and curettage .The details of operative procedure noted with specil emphasis on neonatal outcome, no of blood transfusion , uterine artery ligation, peripartum hysterectomy, and any other intra operative complication was noted .The maternalmorbidity in the form of admission in high dependence area for more than 48 hours was considered morbidity.

This study was approved by the ethical review board of the (king Abdul Aziz specialist hospital) KASH , taif,SaudiArabia.

All data were analyzed using SPSS version 21.0. Data were presented as percentages for categorical variables. Continuous variables were analyzed and compared using Student's -test. Categorical variables were analyzed and compared using Pearson Chi Square and Yates Continuity Corrections and values of $<0.05$ were considered to indicate statistical significance.

\section{Results}

In two year total no of deliveries was 17757 out of that 213 was cases of placenta previa that makes the $1.19 \%$ of placenta previa out of total deliveries .Out of 5498 L.S.C.S, 213 cases were because of placenta previa which make about $3.8 \%$.out of 2131scs 62 cases were done in emergency (29.1\%).and 151 was done as elective cases(70.8). as far as age women's were concerned highest percentage of placenta previa was seen in age group of $31-36$ years $(35.2 \%)$ followed by age group of 26-30years $(26.2 \%)$ as showed in table no one .

Table-1: Distribution of cases by age

\begin{tabular}{|l|l|l|l|l|}
\hline age & Frequency & Percent & Cum Percent & \\
\hline $\mathbf{1 7 - 2 0}$ & 2 & $1.0 \%$ & $1.0 \%$ & \\
\hline $\mathbf{2 1 - 2 5}$ & 36 & $17.1 \%$ & $38.6 \%$ & \\
\hline $\mathbf{2 6 - 3 0}$ & 55 & $26.2 \%$ & $64.8 \%$ & \\
\hline $\mathbf{3 1 - 3 6}$ & 74 & $35.2 \%$ & $100.0 \%$ & \\
\hline $\mathbf{3 7 - 4 0}$ & 43 & $20.5 \%$ & $21.4 \%$ & \\
\hline Total & 213 & $100.0 \%$ & $100.0 \%$ & \\
\hline
\end{tabular}


When we are looking at the gestational age when women had delivered. Two gestational ages are appearing when women had bleeding episode i.e. 30-34 weeks of gestation and 37-38 weeks of gestationtable two .Out of 213 women of placenta previa 144 (67.74\%) women suffered from antepartum hemorrhage from moderate to severe bleeding .All women had lower segment caesarean section as mode of delivery whether in emergency or as an elective procedure dependent upon amount of bleeding, gestational age and condition of mother. All patent had ultrasound done to confirm the localization of placenta and to exclude placenta accreeta or percreeta .Type $1 \mathrm{v}$ placenta previa or major placenta previa turned out to be an important cause of APH i.e. $76.56 \%$.Out of 213 cases of placenta previa 155 cases received more than 3 pints blood transfusion reached up to 8 pints of blood .No patient required transfusion of coagulation factors or platelets transfusion as shown in table three. 14 patient underwent bilateral uterine ligation and because of bleeding and severe nature of placental adherence out of 213 women 56 (26.29\%) had caesarean hysterectomy and 6 patient received injuries to urinary tract in form of bladder injury or uretric injury which could be because of adhesion, excessivebleeding or difficult c/hysrectomy .By the bless of God there was no maternal death recorded in this period of study.

Table 2 Obstetric data in women with placenta praevia.

\begin{tabular}{|l|l|l|}
\hline major & $\mathrm{N}=213$ & Percentage \\
\hline Gestation at admission (weeks & & $\%$ \\
\hline $30-34$ & & \\
\hline $35-36$ & 70 & 32.86 \\
\hline $37-38$ & 63 & 30.49 \\
\hline $39-40$ & 70 & 32.86 \\
\hline $\begin{array}{l}\text { History ofantepartum } \\
\text { haemorrhage (\%) } \\
\text { no bleeding } \\
\text { bleeding from moderate to severe }\end{array}$ & 10 & 4.69 \\
\hline $\begin{array}{l}\text { Type of placenta } \\
\text { praevia (\%) } \\
\text { type II } \\
\text { type 111 } \\
\text { type 1v }\end{array}$ & 69 & 32.36 \\
\hline Confirmed by ultrasound & 144 & 67.64 \\
\hline Pre op MRI & 9 & 4.22 \\
\hline $\begin{array}{l}\text { Mildly adherent } \\
\text { Moderately adherent }\end{array}$ & & \\
\hline Severely adherent & 52 & 24.41 \\
\hline Not adherent & 152 & 71.36 \\
\hline
\end{tabular}

Table 3: maternal outcomes inwomenwithplacenta praevia

\begin{tabular}{|c|c|c|}
\hline & $n-213$ & Percentage $\%$ \\
\hline $\begin{array}{l}\text { Type of lscs } \\
\text { Lower segment } \\
\text { Classical }\end{array}$ & $\begin{array}{l}213 \\
0\end{array}$ & $\begin{array}{l}100 \\
0\end{array}$ \\
\hline $\begin{array}{l}\text { Caesarean } \\
\text { Elective } \\
\text { Emergency }\end{array}$ & $\begin{array}{l}151 \\
62\end{array}$ & $\frac{70.8}{29.1}$ \\
\hline $\begin{array}{l}\text { Post partum haemorrhage } \\
\text { Primary } \\
\text { Secondary }\end{array}$ & 150 & $\begin{array}{l}70.4 \\
------\end{array}$ \\
\hline $\begin{array}{l}\text { Received blood transfusion } \\
\text { (3-8 units of blood }\end{array}$ & 122 & 57.46 \\
\hline \multicolumn{3}{|l|}{ Additional intervention } \\
\hline Bilateral uterine artery ligation & 14 & 6.5 \\
\hline \multicolumn{3}{|l|}{ B-lynch suture } \\
\hline \multicolumn{3}{|l|}{ Internal artery ligation } \\
\hline Hysterectomy & 56 & 26.2 \\
\hline $\begin{array}{l}\text { Any other complication } \\
\text { Bladder injury "uretric injury }\end{array}$ & 6 & 2.8 \\
\hline Matenal death & 0 & 0 \\
\hline
\end{tabular}


Table-4: Relationship of previous obstetric history with placenta previa

\begin{tabular}{|l|l|l|}
\hline Previous uterine surgery & $\mathbf{2 1 3}=\mathbf{n}$ & \%age \\
\hline Previous lscs & 167 & 78.4 \\
\hline $\begin{array}{l}\text { Previous dilatation \& } \\
\text { evacuation }\end{array}$ & 3 & 1.4 \\
\hline primigravida & 7 & 3.6 \\
\hline Previous NVD & 36 & 11.6 \\
\hline
\end{tabular}

When looking at pr obstetric history the greatest association of placenta previa was found with previous caesarean section i.e. about 78.4\%.3.65 \% of primigravida had placenta previa without any risk factors same was the other case where 36 women $(11.6 \%)$ had previous all normal vaginal delivery but presented with placenta previa as far management was concerned all women with APH received a APH protocol as developed in obstetric ward of KASH.followed by admission and operativemanagement depending upon the amount of bleeding ,maternal condition and gestational age .all patient were delivered by lower segment caesarean section ,further operative procedure were done which were depend upon amount of intra operative bleeding, uterine atony ,and adherence op placenta from minimally adherent to severely adherent .

\section{Discussion}

The incidence of placenta accreta has increased and seems to parallel the increasing cesarean delivery rate.This is shown in our study that greatest association of placenta previa was found with previous caesarean section i.e. about 78.4\%. Samefacts are coated in literature by Researchers who have reported the incidence of placenta accreta as 1 in 533 pregnancies for the period of 1982-2002. This contrasts sharply with previous reports, which ranged from 1 in 4,027 pregnancies in the 1970s, increasing to 1 in 2,510 pregnancies in the 1980s The exact etiology of placenta praevia still remains unknown. However, uterine scarring has been speculated as the underlying cause of placenta praevia and it was seen in our study that about $78.4 \%$ had previous lscs same result was shown in other study ${ }^{17}$. As far as association of placenta previa with parity isconcerned we found 7 patients were primigravida with no h/o of assisted reproduction or any previous intra uterine intervention. These finding was in contrast to one study which showed strong relationship of placenta previa with endometriosis and assisted reproduction in primigravida ${ }^{18}$. As far as maternal age is concerned it has been seen that highestprevalence of placenta previa was seen in the age group of between 31 to 36 years of maternal age same results has beenseen in one study ${ }^{19}$. Anotherstudy also showed that the highest prevalence were seen $30 \mathrm{yr}$ and above age group in compare to below $30 \mathrm{yr}$. age group ${ }^{20}$.

Placenta praevia has been reported to be associated with serious maternal morbidity and mortality and also adverse neonatal outcome .One of the major reason of increase maternal morbidity is intra operative blood lose. In the present study, more than half women received more than 3 units of blood and reached up to 8 units and also about more than half women suffered from PPH. about in 14 patient they had bilateral tubal ligation and got less blood lose and different peoples are trying different intraoperative prophylactic technique for reduction of blood lose and less need of blood transfusion ${ }^{21}$.

$78 \%$ percent of the women had history of caesarean section and $1.4 \%$ had history of dilatation and curettage. Caesarean section and dilation and curettage were both recognized risk factors for placenta previa which we observed in our study same result was found in another study ${ }^{22}$. Studies have shown that $49 \%$ were having severely adherent placentaand were anterior in location .same report I found in some studies that thereare higher incidence of placenta accreta in those with anterior placenta as compared to placenta which are posteriorly located ${ }^{23}$.

The risk of having placenta accreta was higher in women with placenta praevia who had previous caesarean deliveries. This can be explained by the implantation of the placenta over the scar, supporting the theory that trophoblast adherence or invasion was enhanced by previous myometrial disruption. In our studies, 33 (49.8) women were having severelyadherent placenta Hysterectomy was carried out for placenta accreta and diagnosis was confirmed by histopathology.

There are several limitations in the present study. The retrospective nature of this study cannot include certain parameters due to limited documentation and exclude potential biases. This study was conducted in the tertiary hospital and hence the sample population does not represent the general population.

\section{Conclusion}

In summary, history of previous lower segment caesarean section were found to be associated increased rate of placenta previa and its severe form i.e. placenta accreta, because of APH they required early delivery with heavy blood loss which need increased intraoperative blood transfusion. Also it was seen that good ultrasound with color Doppler study is the confirmatory test for different degree of adherent placenta from mildly adherent to placenta accreta. It was also concluded that lot of different operative techniques are applied now days to reduce excessive bleeding which is commonly associated with placenta previa this intraoperative 
techniques ranges form uterine artery ligation to hysterectomy .it is also concluded that with good antenatal care we can pick patient who are at high risk of placenta previa and its related risk .

\section{Conflict of Interests}

The authors declare that there is no financial or other conflict of interests related to this paper.

\section{Acknowledgement}

I acknowledge the effort of my student razan flimban and noora aloada in gathering data.

\section{References}

[1]. Yang Q, Wen SW, Oppenheimer L, Chen XK, Black D, Gao J, Walker MC. Association of caesarean delivery for first birth with placenta praevia and placental abruption in second pregnancy. BJOG 2007 May; 114 (5):609-13.

[2]. Yang Q, Wen SW, Phillips K, Oppenheimer L, Black D, Walker MC. Comparison of maternal risk factors between placental abruption and placenta previa.Am J Perinatol. 2009 Apr; 26(4):279-86.

[3]. Salihu HM, Li Q, Rouse DJ, Alexander GR: Placenta previa: Neonatal deathafter live births in the United States. Am J ObstetGynecol2003 188(5):1305-1309.

[4]. Ananth CV, Smulian JC, Vintzileos AM: The effect of placenta previa on neonatal mortality: a population-based study in the United States, 1989 through 1997. Am J ObstetGynecol2003, 188(5):1299-1304.

[5]. Iyasu S, Saftlas AK, Rowley DL, Koonin LM, Lawson HW, Atrash HK: TheEpidemiology of Placenta-Previa in the United-States, 1979 Through1987. Am J ObstetGynecol1993, 168(5):1424-1429

[6]. Brace V, Kernaghan D, Penney G: Learning from adverse clinicaloutcomes: major obstetric haemorrhage in Scotland, $2003-05$. BJOG 2007, 114(11):1388-1396.

[7]. Crane JMG, Van den Hof MC, Dodds L, Armson BA, Liston R: Maternal complications with placenta previa. Am J Perinatol2000, 17(2):101-105

[8]. Bhide A, Prefumo F, Moore J, Hollis B, Thilaganathan B: Placental edge to internal os distance in the late third trimester and mode of delivery in placenta praevia. BJOG 2003, 110(9):860-864.

[9]. E. C. Olive, C. L. Roberts, C. S. Algert, and J. M. Morris, "Placenta praevia: maternal morbidity and place of birth," Australian and New Zealand Journal of Obstetrics and Gynaecology, 2005. vol. 45, no. 6, pp. 499-504.

[10]. E. Sheiner, I. Shoham-Vardi, M. Hallak, R. Hershkowitz, M. Katz, and M. Mazor, "Placenta previa: obstetric risk factors and pregnancy outcome," The Journal of Maternal-Fetal Medicine, 2001 vol. 10, no. 6, pp. 414-419.

[11]. L. Tuzovic, "Complete versus incomplete placenta previa and obstetric outcome," International Journal of Gynecology and Obstetrics 2006 vol. 93, no. 2, pp. 110-117.

[12]. C. Onwere, I. Gurol-Urganci, D. A. Cromwell, T. A. Mahmood, A. Templeton, and J. H. van der Meulen, "Maternal morbidity associated with placenta praevia among women who had elective caesarean section," European Journal of Obstetrics \& Gynecology and Reproductive Biology, 2011 vol. 159, no. 1, pp. 62-66.

[13]. M. Schneiderman and J. Balayla, "A comparative study of neonatal outcomes in placenta previa versus cesarean for other indication at term," Journal of Maternal-Fetal and Neonatal Medicine, vol. 26, no. 11, pp. 1121-1127, 2013. View at Publisher . View at Google Scholar.

[14]. Sheiner E, Shoham-Vardi I, Hallak M, Hershkowitz R, Katz M, Mazor M. Placenta previa: obstetric risk factors and pregnancy outcome. J Matern Fetal Med. 2001 Dec; 10(6):414-9.

[15]. Nasreen F. Incidence, causes and outcome of placenta previa. J Postgrad Med Inst 2003; 17: 99-104

[16]. Bahar A, Abusham A, Eskandar M, Sobande A, Alsunaidi M. Risk factors and pregnancy outcome in different types of placenta previa.JObstetGynaecol Can. 2009 Feb; 31(2):126-31.

[17]. T. Rosenberg, G. Pariente, R. Sergienko, A. Wiznitzer, and E. Sheiner, "Critical analysis of risk factors and outcome of placenta previa," Archives of Gynecology and Obstetrics, 2011 vol. 284, no. 1, pp. 47-51.

[18]. Abdul Ghani Nur Azurah, ${ }^{1}$ Zakaria Wan Zainol, ${ }^{1}$ Pei Shan Lim,,${ }^{1}$ MohdNasir Shafiee, ${ }^{1}$ Nirmala Kampan, ${ }^{1}$ Wan Syahirah Mohsin, ${ }^{1}$ NorfilzaMohd Mokhtar, ${ }^{2}$ and Muhammad Abdul Jamil Muhammad Yassin . Factors Associated with Placenta Praevia in Primigravidas and Its Pregnancy Outcome. Scientific World Journal Volume 2014 (2014),

[19]. Cieminski $A^{1}$, Długołecki F Relationship between placenta previa and maternal age, parity and prior caesarean deliveries.Ginekol Pol. 2005 Apr; 76(4):284-9.

[20]. Hossain GA1, Islam SM, Mahmood S, Chakraborty RK, Akhter N, Sultana SPlacentaprevia and it's relation with maternal age, gravidity and cesarean section .Mymensingh Med J. 2004Jul; 13(2):143-8.

[21]. Ashok R. Anand, Deepti Gupta, AnjuPrasad.Reducing intraoperative lower segment blood loss in placenta previa with Ashk Anand stitch. Int J ReprodContraceptObstet Gynecol. 2013; 2(2): 135-140.

[22]. M.A.P.C. van Ham, P.W.J. van Dongen, and J. Mulder, "Maternal consequences of caesarean section. A retrospective study of intra-operative and postoperative maternal complications of caesarean section during a 10-year period," European Journal of Obstetrics Gynecology and Reproductive Biology, 1997 vol. 74, no. 1, pp. 1-6.

[23]. J. Hasegawa, R. Matsuoka, K. Ichizuka et al., "Predisposing factors for massive hemorrhage during Cesarean section in patients with placenta previa," Ultrasound in Obstetrics and Gynecology, vol. 34, no. 1, pp. 80-84, 2009. 